\title{
A Química na Net, a Net da Química
}

\author{
Luis Alberto P. Rosa*, João Paulo Leal*(a)
}

O recurso às novas tecnologias tem aumentado em volume e em importância nos últimos anos. Para facilitar a consulta

criou-se uma base de dados que compila "sites" de Internet em língua portuguesa, subordinados à temática da Química.

Nesta comunicação, apresenta-se o trabalho desenvolvido, dando especial relevo ao tratamento estatistico dos dados.

\section{INTRODUÇ̃̃O}

\section{Objectivos}

O recurso às novas tecnologias para a pesquisa e recolha de informação sobre os mais variados temas compete, quase de igual para igual, com outras fontes tradicionais da informação, do conhecimento e do saber que gozavam de exclusividade, até há pouco mais de uma década atrás. Assim sendo, surgiu a convicção de que seria de grande utilidade a construção de uma Base de Dados que compilasse, num formato de fácil acesso, um conjunto de informação respeitante a sites de Internet exclusivamente em língua portuguesa, subordinados à temática da Química.

Para a sua concretização este trabalho abordou quatro objectivos. O primeiro objectivo traduziu-se na realização da pesquisa, levantamento, e identificação de sites da Internet em língua portugue$\mathrm{sa}$, de temas e matérias relacionados com a Química, sendo os dados desta compilação guardados em formato "Excel". O segundo objectivo consistiu na apreciação desses sites de acordo com determinados critérios de classificação. O terceiro objectivo traduziu-se na construção de uma base de dados relacional utilizando o programa "Access", sistematizando toda a informação obtida. Finalmente o quarto objectivo teve em vista o tratamento estatístico da informação constante da Base de Dados. Nesta comunicação apresenta-se o trabalho desenvolvido, com especial ênfase no último objectivo.

\footnotetext{
Escola António Sérgio, 2735-228 Cacém - Portugal

* (a) Departamento de Química, Instituto Tecnológico e Nuclear, 2686-953 Sacavém - Portugal e Departamento de Química e Bioquímica, Faculdade de Ciências, Universidade de Lisboa, 1749-016 Lisboa - Portugal jpleal@itn.pt
}

\section{IMPORTÂNCIA PARA OS PROFESSORES E PARA OS ALUNOS}

Para os professores, determinados sites encerram um enorme potencial, valorizador das planificações e da estratégia de sala de aula, sobretudo se aí se dispuser de um projector que permita o visionamento de esquemas, diagramas, tabelas ou fotografias que se julguem particularmente elucidativos e facilitadores da aprendizagem, enriquecendo dessa forma a lição em questão. "Para muitos professores, que acreditam na importância de um currículo centrado nas necessidades dos alunos, a Internet constitui um excelente meio de motivação, pois pode ir ao encontro das suas necessidades. Eles podem informar-se sobre pontos do seu interesse e encontrar respostas a muitas das suas perguntas." [1] Este facto é em grande parte decorrente da recente evolução e divulgação das Novas Tecnologias exigindo inevitáveis mudanças nos métodos de ensino e de pensamento, bem como na abordagem dos problemas. "Ninguém deve ficar alheio às novas realidades, visto os alunos aderirem normalmente com muito entusiasmo a estas Novas Tecnologias. A Internet é um desses recursos, pois permite uma participação activa e divertida, que se afasta do ensino tradicional, sendo por essa razão bastante motivadora." [2]

Todos os meios são legítimos, nessa luta contra a desmotivação e a desvalorização da escola tradicional. "Por todas estas razões, o professor tem de fazer um esforço, acompanhar toda essa mudança e não ter medo de novas experimentações, nem das Novas Tecnologias. ..., não podemos desprezar todas as ferramentas que passámos a ter ao nosso dispor e que nos podem auxiliar na nossa tarefa." [3]

Para os estudantes, os conteúdos dos sites de Internet, objecto da sua pesquisa, representam seguramente um excelente complemento, relativamente às habituais fontes de informação e saber. No entanto, o Sistema Educativo actual parece encerrar hoje alguns aspectos pouco motivadores para os alunos. Segundo Ponte [4] "os alunos têm um papel muito passivo, já que pouca ou nenhuma participação Ihes é solicitada. Por este motivo a escola pouco significado tem para muitos alunos, que por ela apenas demonstram grande desinteresse". Sabemos, de resto, da nossa experiência do dia-a-dia que nenhum professor será capaz de obter resultados satisfatórios de um aluno que não se sinta motivado para a escola, em geral, ou para uma disciplina em particular, e disposto a despender algum esforço para obter o sucesso. "Para a desmotivação dos alunos, muito contribui o facto das escolas estarem de costas viradas para a realidade actual e não acompanharem o desenvolvimento tecnológico, distanciando-se assim da vida em que os alunos estão inseridos." [5]

É reconhecida a grande empatia e interesse que os alunos revelam pelas Novas Tecnologias, designadamente pela Internet. Refere Freitas [6] que "presentes no quotidiano, as Novas Tecnologias já atraem quem as utiliza, tanto pela facilidade do seu uso como pelas possibilidades que proporcionam, sendo excelentes alternativas, à aprendizagem escolar tradicional". Roerden [7] refere que "os alunos que recorrem à Internet, dizem que nem se apercebem de que estão a apren- 
der enquanto utilizam a $W e b$, porque se estão a divertir imenso e, normalmente, aprender é uma coisa séria e difícil".

Aqueles que navegaram na Internet experimentaram já alguma frustração quando pretendiam, de uma forma rápida, encontrar uma dada informação. Uma das vantagens da criação de um instrumento deste tipo reside essencialmente na poupança de tempo e facilidade na busca obtidas por quem dele futuramente fizer uso.

Acresce a este facto, um outro sobre a qualidade científica de um determinado site. Nem toda a informação disponibilizada na Internet é de confiança. O facto de ter uma classificação anexa ao site que dá conta da sua organização, apresentação e correcção científica pode também ser uma mais-valia em especial para os estudantes.

\section{Critérios Utilizados}

Uma questão fundamental foi definir quais os critérios de consulta segundo os quais este trabalho devia ser estruturado. Estes critérios devem ser de utilidade para a pesquisa a realizar pelo provável universo de utilizadores, um grupo maioritariamente constituído por estudantes e professores. Para tal, e apesar de algumas ideias próprias sobre quais deveriam ser esses critérios, realizou-se uma consulta sobre os critérios apontados por trabalhos existentes na literatura.

Os critérios encontrados sobre avaliação de sites foi escasso mas encontraram-se também algumas referências sobre "Avaliação de software informático" ou "Avaliação de software educativo". Um site da Internet apresenta muitas semelhanças com um software informático, pelo que os critérios para a classificação de qualquer deles, não sendo iguais, apresentam alguns aspectos comuns. Assim sendo, uma análise desses documentos foi também muito útil.

Roblyer [8], sobre software educativo, refere algumas áreas a ter em conta das quais se salientam:

Projecto Instrutivo (nessa área são incluídas a explanação dos objectivos, as capacidades pré-requeridas, o nível de dificuldade, a importância educativa, entre outros);

Uso pelo Professor (são mencionados os aspectos ligados à facilidade de uso, à integração curricular e à adaptabilidade);

Apresentação (os gráficos, a animação, a cor, o som e a apresentação gráfica).

O jornal de educação "The Educational Technology Journal" [9] define alguns critérios possíveis a ter em conta, como:

Eficiência (consegue-se encontrar o que se pretende, de modo fácil e rápido?; o site não tem informação inútil?);

Organização (a informação é apresentada de forma lógica?; pode ser consultada sem perder tempo?).

A "Baltimore County Public Library" [10] aponta também uma série de critérios relevantes:

Utilização (É amigável? - Permite o uso da informação de modo fácil?);

Organização (A informação é apresentada de forma lógica?); Índice (Possui um índice bem feito?);

Clareza (As páginas são claras?);

Botões (Os botões são consistentes ao longo do site?)

Links (São claros e devidamente identificados?).

A Universidade de Saskachetwan, no Canadá, [11] apresenta critérios para a análise de sites na Internet, de entre os quais se destacam:

O Público-alvo (Indica claramente o nível académico das audiências alvo? Possui conteúdos e actividades de acordo com o nível académico da audiência alvo? Reconhece que os estudantes aprendem de maneiras diferentes?);

A Objectividade ( $O$ conteúdo está livre de polarização comercial, política, sexual ou racial? Indica objectivos curriculares que correspondam ao seu conteúdo?);

EstéticalApresentação (A apresentação está adequada ao nível da audiência?);
Navegação (A página de entrada fornece acessos fáceis ao resto do web site? Os links são mantidos actualizados?).

Considerando os critérios apresentados e visto que a nossa base de dados versa uma área científica específica, considerou-se que alguns critérios referidos nos trabalhos analisados não se adaptam ao nosso caso, como por exemplo, o critério sobre a polarização comercial, política, sexual ou racial. Outros critérios foram, ainda, reformulados ou adaptados, surgindo com um léxico distinto, mais de acordo com o espírito e objectivo do trabalho.

Como resultado da conjugação da consulta realizada a esses trabalhos com as nossas próprias concepções, resultaram os critérios que incluímos na base de dados e que se afiguraram os mais adequados para o fim em vista e que, de certa forma, constituem a sua "espinha dorsal".

\section{ESTRUTURA E DESENVOLVIMENTO}

A base de dados foi estruturada de acordo com os critérios acima referidos e que se consideraram relevantes para o fim em vista, isto é, informar o utilizador, de uma forma rápida e tanto quanto possível esclarecedora acerca das especificidades do conteúdo de um site ou página ou, ainda, pôr à sua disposição um conjunto organizado de informação, que o possa ajudar a seleccionar, se disponível, de entre vários endereços e para um mesmo tema, a informação que para ele, nesse momento, é a mais adequada, tornando dessa forma a sua pesquisa mais rápida e eficaz.

Na Tabela 1, apresentada na página seguinte, referem-se os critérios seleccionados para a base de dados bem como uma descrição de cada um deles.

Todos estes itens são apresentados de forma clara na ficha da base de dados (ver Figura 1 na página seguinte) permitindo assim uma consulta rápida e eficiente. 
Tabela 1 Critérios usados na classificação dos sites

\begin{tabular}{|c|c|}
\hline Endereço & Identifica o endereço electrónico do site em causa. \\
\hline Tema abordado & Identifica o tema ou temas. \\
\hline Sub-tema/s abordado/s & Identifica o sub-tema ou sub-temas. \\
\hline Tipo & Especifica se o endereço é de uma página, de um programa ou ambos. \\
\hline Aplicação & Esclarece se o tema ou temas tratados se destina/m ao estudo, ao ensino ou a ambos. \\
\hline Editor & Identifica a entidade ou pessoa responsável pela criação do site. \\
\hline Nome do site & Indica o nome do site, do Programa ou da/s Página/s. \\
\hline \multicolumn{2}{|l|}{ Nível Básico (com reservas) } \\
\hline \multicolumn{2}{|l|}{ Nível Secundário (com reservas) } \\
\hline Nível Superior & $\begin{array}{l}\text { Estes vários critérios esclarecem se os pré-requisitos adequados para a perfeita compreen- } \\
\text { são dos conteúdos do site se situam ao nível do Ensino Básico (com ou sem reservas), } \\
\text { Ensino Secundário (com ou sem reservas) ou do Ensino Superior ou Universitário. }\end{array}$ \\
\hline Questões & Indica se o site inclui questões sobre o tema. \\
\hline Texto & $\begin{array}{l}\text { O site é constituído por texto, devidamente estruturado, isto é, não se limita a algumas } \\
\text { curtas frases. }\end{array}$ \\
\hline Exercícios de aplicação & Indica se o conteúdo do site inclui um ou vários exercícios de aplicação ou problemas. \\
\hline $\begin{array}{l}\text { Esquema/s; Gravura/s; Fotografia/s; } \\
\text { Animações; Vídeo/s }\end{array}$ & $\begin{array}{l}\text { Os vários itens indicam se o site inclui esquemas, gravuras, fotografias, animações ou vi- } \\
\text { deos. }\end{array}$ \\
\hline Apresentação/organização & $\begin{array}{l}\text { Faz referência ao nível de qualidade, apresentação e organização da informação do site. É } \\
\text { classificado numa escala com os valores } 0,1,2,3 \text { e } 4 \text {; respectivamente; Não classificado, } \\
\text { Muito fraco, Fraco, Médio e Bom. }\end{array}$ \\
\hline Número de páginas & Dá uma ideia da dimensão do site. \\
\hline País de origem & Identifica qual o país de origem do site. \\
\hline
\end{tabular}

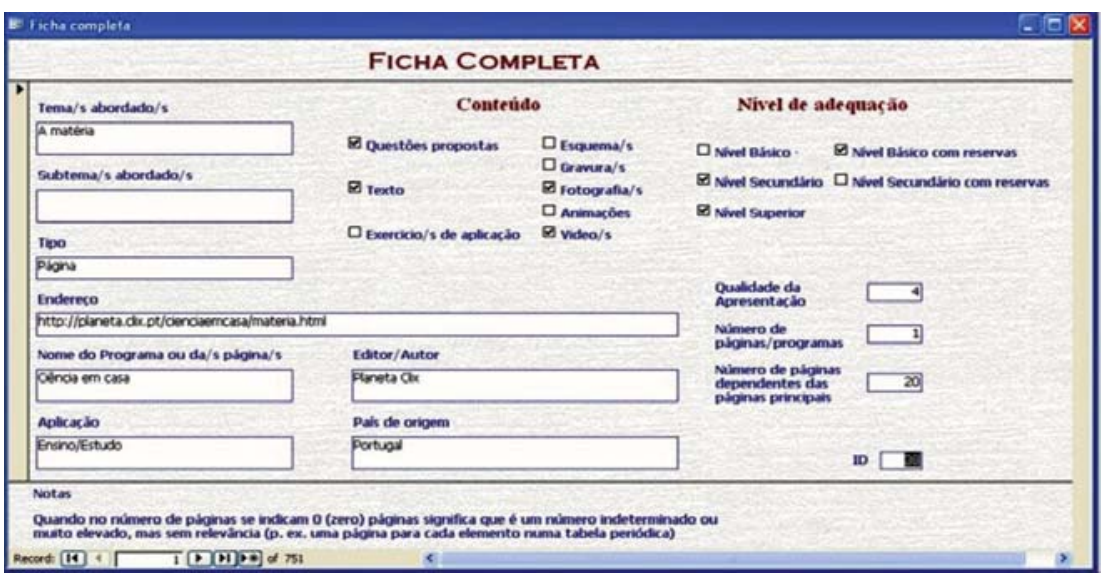

Figura 1 Exemplo de ficha da base de dados em Access mostrando os vários campos com a respectiva informação

\section{LIMITAÇÕES}

A dinâmica da Internet impõe um carácter relativamente efémero, no médio e longo prazo, para um trabalho desta natureza, não dispensando, por essa razão, actualizações periódicas. O inevitável, porém desejável, aparecimento de novos sites, assim como o esperado desaparecimento de outros assim o determina. Condicionantes para a entrada em determinados sites, como por exemplo a obrigação, à cabeça, do pagamento de uma avença, e não apenas a realização de um registo, podem ser também factores limitativos para alguns utilizadores. Este trabalho não se esgota, portanto, nesta fase. É uma tarefa que jamais estará concluída, precisamente pela dinâmica que caracteriza a Internet.

A apreciação de alguns sites à luz de alguns critérios gerou, por vezes, algumas dúvidas e indecisões, já que o seu conteúdo, de acordo com esse/s critério/s, se afigurou de mais difícil classificação. De qualquer modo, como em tudo, compromissos tiveram que ser assumidos, embora estejamos convictos que o resultado final não foi significativamente afectado.

\section{ANÁLISE ESTATísticA}

Utilizou-se o volume de informação contido na base de dados e procedeu-se à sua avaliação e interpretação de acordo com determinados parâmetros. Destas consultas podem retirar-se ensinamentos preciosos.

Na Figura 2 apresenta-se um gráfico de barras com todos os temas que possuem pelo menos duas entradas. Existem 106 outros temas com apenas uma entrada e que não são mostrados na figura. Pode ver-se que o tema mais abundante é Química Orgânica com 122 entradas, o que não espanta devido à abrangência e riqueza de tal tema. Acima das 15 entradas aparecem também O Átomo (24), Experiências (16), História da Química (16), Ligação Química (22), Química Geral (20), Química Inorgânica (16), Soluções (30) e Tabela Periódica (23). 


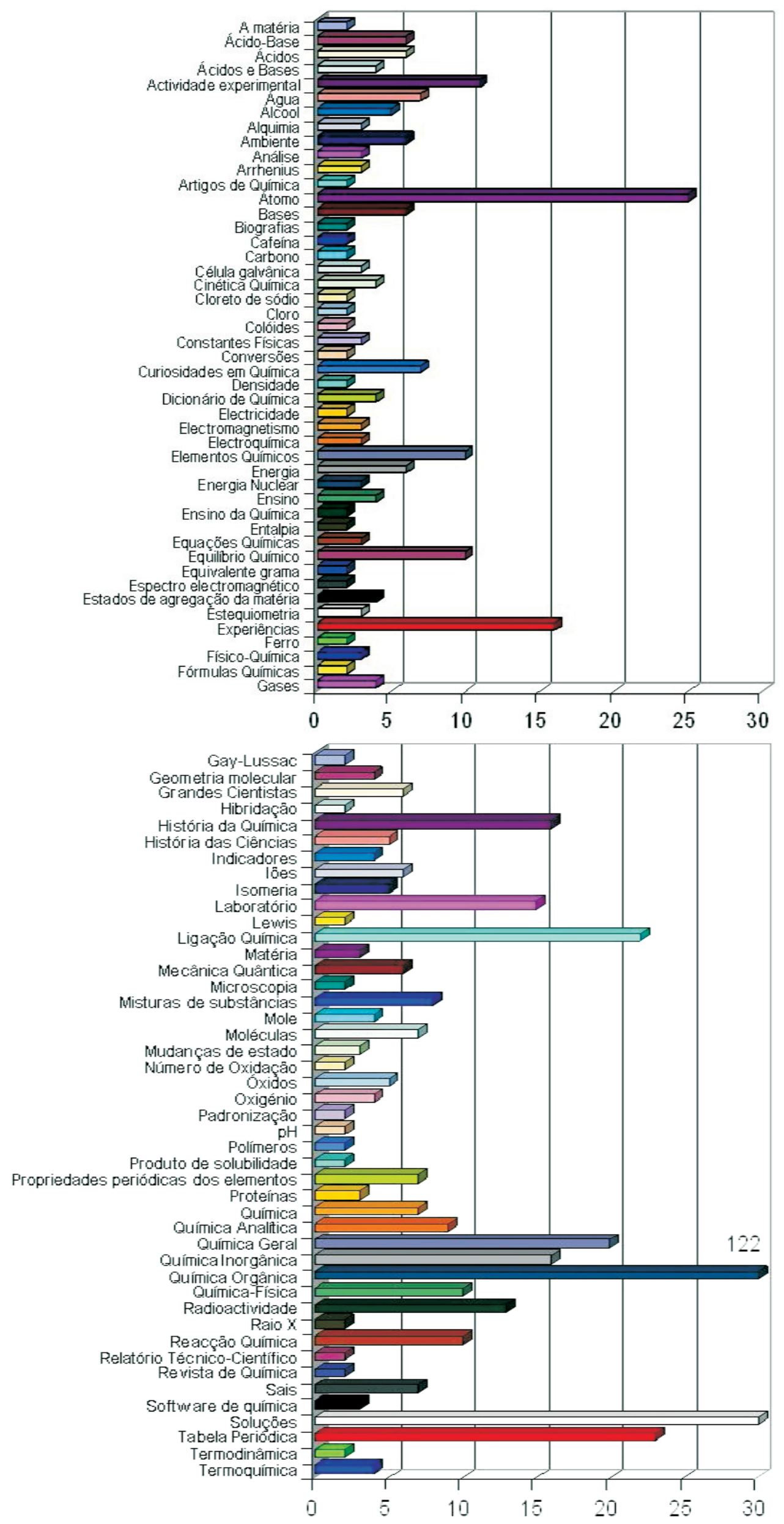

Figura 2 Temas existentes na Base de Dados com mais de duas entradas 
Na Figura 3 apresenta-se a distribuição dos vários sites em função da sua aplicação preferencial, isto é, se estão mais vocacionadas para servirem para o Ensino em Sala de Aula (10\%), para o Estudo $(28,6 \%)$ ou se poderão ser usadas em ambas as situações (59,5\%). Devido à natureza dos assuntos abordados não é estranho que a maioria possa ser utilizada com ambas as finalidades. Existem ainda percentagens marginais de sites que apenas contêm alguma informação pouco elaborada $(0,7 \%)$ ou curiosidades $(1,7 \%)$.

No que se refere ao país de origem $87,2 \%$ dos sites estão localizados no Brasil e 12,7\% em Portugal, existindo um único sediado nos Estados Unidos da América (Figura 4). Tal distribuição reflecte o facto de nos termos cingido a sites em língua portuguesa e ao muito maior número de utilizadores da Internet, estudantes e professores existentes no Brasil quando em comparação com Portugal.

Um dos aspectos importantes é a classificação da Apresentação/Organização da página assim como a sua correcção científica. Uma página classificada com Bom dá manifestamente mais confiança do que uma classificada com Fraco. Verifica-se, Figura 5 , que uma grande maioria dos sites tem uma classificação Média (67,5\%) sendo as percentagens dos que se destacam pela positiva (Bom 16,6\%) e pela negativa (Fraco 15,4\%) idênticas. As duas entradas classificadas como Muito Fracas não são significativas no universo em análise.

A avaliação da qualidade não difere significativamente se for feita independentemente para os sites sediados no Brasil ou em Portugal (para o único site sediado nos EUA não se pode fazer uma análise estatística). No Brasil a distribuição é de 15\% com nota Bom, $69 \%$ com Médio e 16\% com Fraco. Para os sites localizados em Portugal 24\% têm nota Bom, 66\% nota Médio e $9 \%$ com nota Fraco.

Outro aspecto interessante é ver para que nível de ensino estão os sites mais vocacionados. Convém relembrar que os sites adequados para o Ensino Básico também o são para os níveis superiores de ensino. Na figura 6 apresenta-se o número de sites adequados a cada um dos níveis de ensino. Vemos

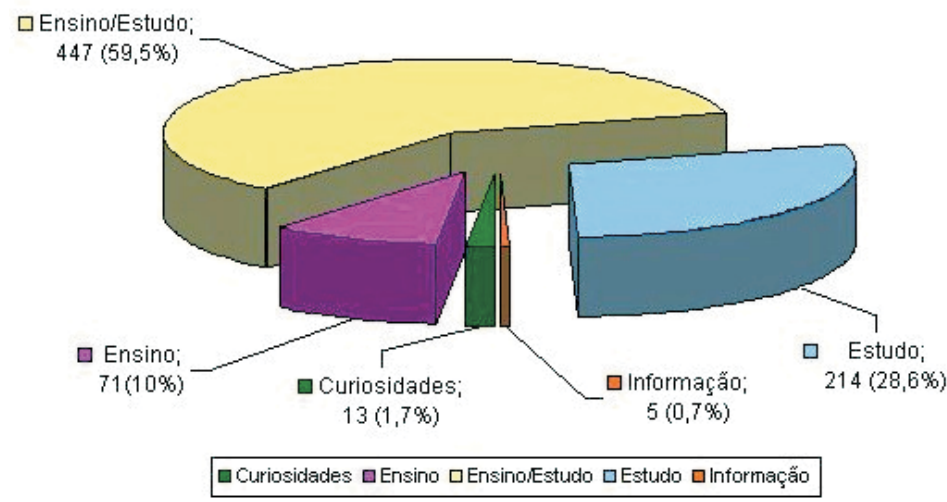

Figura 3 Resultado da análise realizada de acordo com o critério "Aplicação do site". O gráfico mostra o número de sites classificados de acordo com esse critério

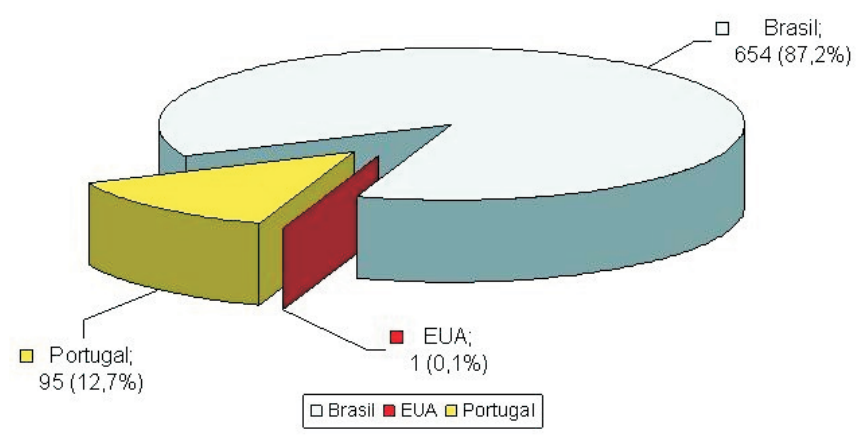

Figura 4 Resultado da análise realizada de acordo com o critério "País de origem"

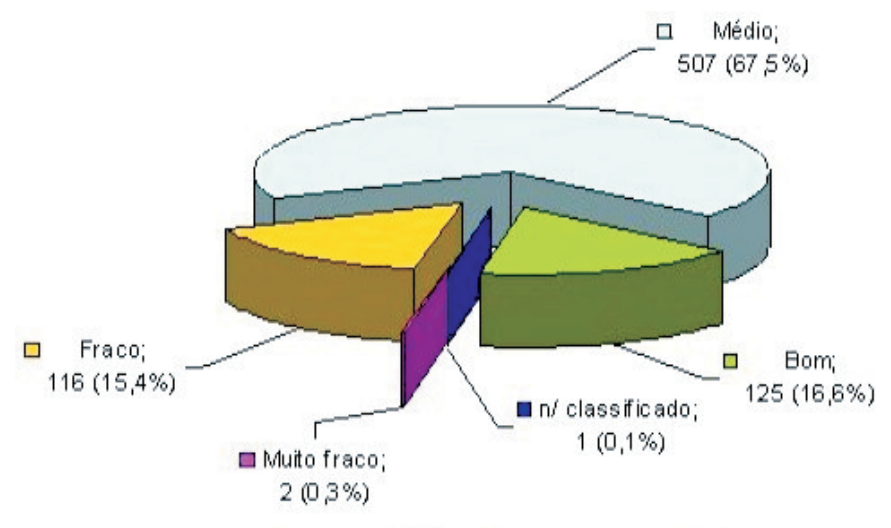

- $n /$ classificado $\mathbf{\square M / F r a c o \square ~ F r a c o ~ \square ~ M e ́ d i o ~ \square B o m ~}$

Figura 5 Resultado da análise realizada de acordo com o critério "Apresentação/Organização".

O gráfico mostra o número de sites classificados de acordo com o nível correspondente

que, embora com algumas reservas de mais 259 que podem ser usados no Sealguns conteúdos em 215 sites, 345 cundário e 147 que apenas são adequasites podem ser usados para o Ensino dos ao Ensino Superior. Básico, existindo para além desses

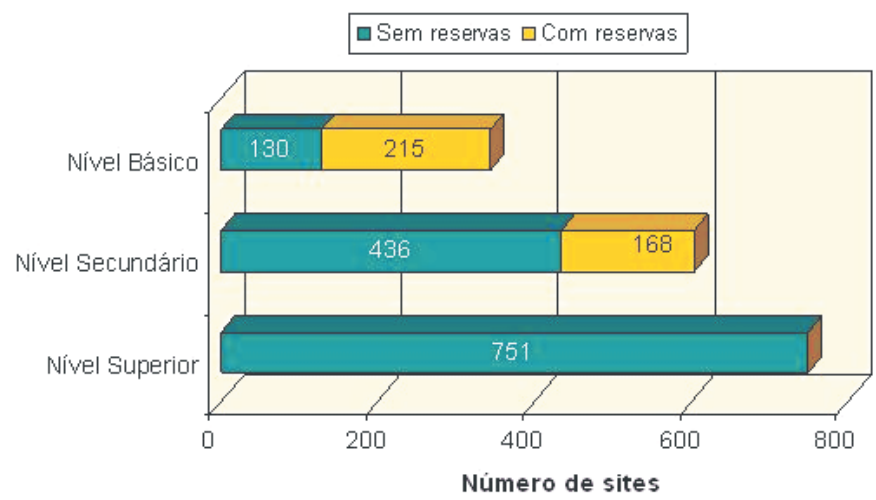

Figura 6 Gráfico comparativo dos sites adequados para os três níveis de ensino. Discrimina entre os que envolvem e os que não envolvem restrições ou reservas 
Numa análise mais fina, podemos também ver como, para cada nível de ensino os sites se caracterizam pelo seu tipo como uma Página, um Programa ou como ambos (Tabela 2). A percentagem dos que são caracterizados como sendo simultaneamente Página e Programa é diminuta e a esmagadora maioria dos sites caracteriza-se como Página. De notar ainda que há 18 programas desenvolvidos para o Ensino Básico, apenas mais 8 aplicáveis aos Ensino Secundário e nenhum desenvolvido especificamente para o Ensino Superior.

Muitas vezes quando se consulta a Internet estamos interessados especificamente num determinado formato de informação (foto, vídeo, etc.). É por isso importante que existam estes critérios de procura. O que se pode constatar é que à medida que o formato se torna mais complexo, o número de sites que o disponibilizam é menor (Figura 7). Assim temos que num total de 751 sites, 414 têm Esquemas, 120 Gravuras, 69 Fotografias, 40 Animações e apenas 7 têm vídeos.

\section{Conclusão}

A pesquisa na Internet, para a construção da base de dados, foi realizada entre 2002 e 2004, e por esse motivo a base de dados em si (e que os autores podem fornecer a pedido dos interessados) estará hoje algo desactualizada. No entanto os critérios usados bem como a análise estatística feita continuam válidos hoje como nessa altura. Apesar do tempo passado, a maioria dos endereços continua activo. Assim sendo, parece-nos que uma das vantagens para professores, estudantes ou, de um modo geral, potenciais utilizadores de um trabalho desta natureza, se traduz na poupança de tempo nas pesquisas realizadas, evitando demoras desnecessárias ou desmotivadoras, bem como uma maior objectividade na busca. O acesso fácil encoraja e estimula a pesquisa.

\begin{tabular}{|c|r|r|r|}
\hline & Página & Programa & Página/ Programa \\
\hline Ensino Básico & 323,0 & 18,0 & 1,0 \\
$\%$ & 94,4 & 5,3 & 0,3 \\
\hline Ensino Secundário & 575,0 & 26,0 & 1,0 \\
$\%$ & 95,5 & 4,3 & 0,2 \\
\hline Ensino Superior & 724,0 & 26,0 & 1,0 \\
$\%$ & 96,4 & 3,5 & 0,1 \\
\hline
\end{tabular}

Tabela 2 Distribuição dos sites como Página e/ou Programa conforme os níveis de ensino

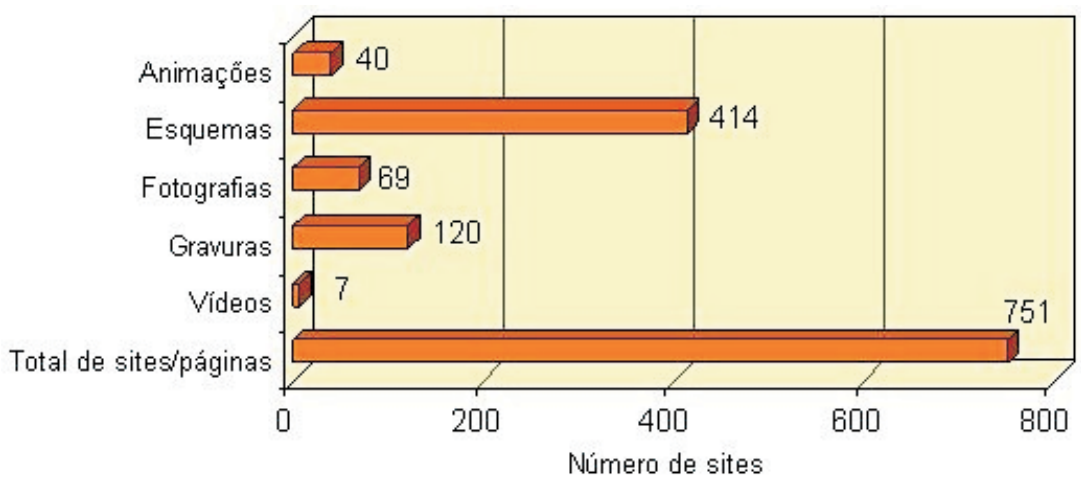

Figura 7 Resultado da contagem dos sites que incluem animações, esquemas, fotografias, gravuras e vídeos

Os autores esperam que se possa brevemente actualizar a base de dados e assim, para além de ter endereços actualizados e alguns novos, ter uma noção do desenvolvimento que a comunidade de sites em língua portuguesa relacionados com a Química sofreu nos últimos anos.

\section{REFERÊNCIAS}

[1] R. Santos, Tese de Mestrado, Universidade Portucalense Infante D. Henrique, Portugal, 2001.

[2] T. A. Eça, Netaprendizagem: A Internet na Educação, Porto Editora, Porto, 1998.

[3] A. M. Eusébio, Tese de Mestrado, APM-Escola Superior de Educação de Lisboa, Portugal, 1995.

[4] J. P. Ponte, As Novas Tecnologias e a Educação, Texto Editora, Lisboa, 1997.
[5] M. M. N. Santos, in Tecnologias de Informação e Comunicação na Aprendizagem; C. Freitas, M. Novais, V. R. Baptista, J. L. Ramos, eds.; IIE, Lisboa, 1997, p. 21-29.

[6] C. V. Freitas, in Tecnologias de Informação e Comunicação na Aprendizagem; C. Freitas, M. Novais, V. R. Baptista, J. L. Ramos, eds.; IIE, Lisboa, 1997, p. 31-39.

[7] L. P. Roerden, Net Lesson: Web-Based Projects for Your Classroom; O'Reilly \& Associates, Inc.: USA, 1997.

[8] M. D. Roblyer, The Executive Educator 34-35 (1983) 38-39.

[9] http://www.fno.org/jun97/eval.html acedido em Janeiro de 2005.

[10] http://www.bcpl.net/ sullivan/modules/tips/eval.html acedido em Janeiro de 2005.

[11]http://www.usask.ca/education/ coursework/802papers/bokcaisse/ bokcaisse.pdf acedido em Janeiro de 2005. 